\title{
Assessing the Microlevel Impacts of Sin Tax Law on Cigarette Consumption: A Case Study for Mahaplag, Leyte, Philippines
}

\author{
Lemuel S. Preciados $^{1^{*}}$ and Jayson E. Carcajente ${ }^{1}$ \\ ${ }^{I}$ Departement of Economics, Visayas State University
}

\section{ABSTRACT}

Examined in this study were the effects of Sin Tax Law at the microlevel. Using the before-and-after method of analyzing impacts, we applied a multiple regression analysis incorporating difference-in-difference approach of econometric estimation. It appeared that youths had significantly lower cigarette consumption after the implementation of this law. This suggests that Sin Tax Law (STL) discouraged the youth from smoking. In contrast, consumption of cigarettes among adults did not change significantly implying that the tax induced price-increase was relatively less effective. Therefore, it is recommended that there should be specific policies targeting adult smokers to inhibit them from consuming more cigarettes. Results also provide important lessons for future research in monitoring and evaluating public policies.

Keywords: smokers, adults, youth, difference-in-difference

\section{INTRODUCTION}

The effectiveness of the implementation of Sin Tax Law in the Philippines remains contentious. Current debates between tobacco companies, health authorities, and policy-making bodies have surface extensively in different forums concerning the extent of the impact of the Sin Tax Law. There have been many surveys and studies conducted nationwide on assessing the effects of Republic Act 10351 on the Sin Tax Law since its January 2013 implementation, but only a few studies done using econometric analysis to clearly assess the impacts of the said law and identify the determinants of cigarette consumption across different age groups (Ulep 2012). This study aimed to explore the efficacy of this method to assess impact of the Law at the micro-level perspectives using a case study.

In $2009,28.3 \%$ of adults in the Philippines were smokers, and the

Correspondence: Lemuel S. Preciados Address: Department of Economics, Visayas State University Email: lemuel.preciados@vsu.edu.ph

DOI: $10.32945 /$ atr3918.2017 
proportion of smokers is higher among the poor segments of the population in the country (Ulep 2012). There are many factors that determine the smoking participation and cigarette demand of youth and adults. One of those factors is excise tax/price. Numerous studies used cross-sectional data to evaluate the effect of price and taxes on smoking behavior. Douglas and Hariharan (1994) were the first to model smoking initiation using advanced econometric techniques (a split population duration model). They concluded that increases in cigarette excise tax, which increase the price of cigarettes had no influence on individuals' decisions to start smoking. The same as the previous study of Grossman et al (1983) which uses the 1974, 1976, 1977, and 1979 National Survey on Drug Abuse which also found that the decision to smoke is negatively related to price. However, they found that once the decision to smoke had been made, average consumption decisions by youth smokers are virtually unresponsive to price.

Lewit, Coate \& Grossman (1981) estimated smoking participation equations for all youth as well as cigarette demand equations for youth smokers. This allows them to distinguish the effect of price on the decision to smoke from its impact on cigarette consumption by smokers. They estimate that the price elasticity of demand among youths is -1.44 . This explains why youth are responsive to the increase of price. On the other hand, Bishop and Yoo (1985) investigated the determinants of cigarette consumption, including taxes, the 1950's health scare, and the advertising ban. They found that taxes were more effective in reducing the consumption than the health scare or the advertising ban. In fact, the latter two had little effect on reducing smoking. Therefore, it has been shown that levying taxes on cigarettes would be an effective means of reducing the consumption of cigarettes.

In some studies, they used education as a determinant of smoking. Chaloupka (1991) found that less educated individuals behaved more blindly than more educated individuals. Meaning, as people become more educated, they were more aware of the true opportunity costs of smoking. Xiaohui Hou et al (2015) confirmed that people who could not read or were uneducated were more likely to smoke. This presents challenges in terms of broader tobacco control. If the smokers cannot read, regulations such as health warnings on tobacco packages and brochures highlighting the harmful effects of smoking on health will not be effective.

Chaloupka (1991) found that women acted less blindly and were less responsive to price than men. He also found that restrictions on smoking in public places had a significant negative impact on average cigarette consumption. If people were restricted to smoke, their consumption would definitely decrease.

Income would also determine the trend of cigarette consumption and 
on why people participate in smoking. Harris (1985), found that people in poverty were more likely to smoke. He looked at incomes among age groups and in all age groups. Results revealed that those individuals with lower incomes were smokers, while those with higher incomes were not. Wasserman et al (1991) provided evidence that adult demand for cigarettes falls as income rises, suggesting cigarettes are an inferior rather than normal good. If this is true for youth demand, the income and substitution effects of a price change work in opposite directions and the uncompensated price elasticity falls (in absolute value) as cigarettes' budget share rises.

In the study of Nguyen (2012) on determinants of smoking behaviour, he found that widowed people were more likely to smoke. Loss of spouse increased the probability of smoking by around 11.7 percentage points. Widowed people also had lower probability of quitting smoking. He also found out that household size had a positive and significant effect on the probability of smoking cessation. It implies that people might tend to quit smoking if there are children or old people in their households.

The formula of Blecher and van Walbeek (2008) found out that cigarette (both local and foreign brands) became cheaper to buy each year as shown by the annual decrease in Relative Income Price (RIP). However, but after the Sin Tax Law took effect, RIP noticeably have increased. Kan's (2007) formula (cigarette price divided by average daily salary) showed the same pattern. RIP was observed to be decreasing from 2000 to 2012, until it increased in 2013. These studies indicate that the Sin Tax Law made the price the less affordable to drive down consumption levels.

A fundamental building block of economic theory is the fact that increasing (or decreasing) the price of a commodity reduces (or increases) demand for that commodity. As reviewed by Manning et al (1991), their estimates of the price elasticity of cigarette demand ranges from -0.22 to 1.0. Based on their expert evaluation of the reliability of the different available estimates, the consensus of a National Cancer Institute sponsored group put the price elasticity in a narrower range, from -0.3 to -0.5 (National Cancer Institute 1993). Similarly, in this current study the price elasticity of demand for cigarette is estimated.

Additionally, some studies that collected data from individuals also allow researchers to assess how different population groups tend to respond to changes in price. Using data from the 1976 National Health Interview Survey (NHIS), Lewit and Coate (1982) found that younger smokers were more price responsive than older smokers. Evans and Farrelly (1995) pooled data from 13 of the National Health Interview Surveys conducted from 1976 through 1992 to examine the demand for cigarettes by young adults (ages 18 through 24 years) and adults (ages 25 through 39 years and ages 40 and older). Their findings are consistent with 
the work by Lewit and Coate (1982) in that they find that the price responsiveness of cigarette demand decreases with age. The overall price elasticity of demand is -0.63 for young adults which is approximately $50 \%$ higher than those ages 25 through $39(-0.42)$. However, the study of Chaloupka (1991) estimated lower elasticities. His study reported that youths and young adults (ages 17 to 24) are found to be less responsive to price than older groups, which is an opposing result with the study of Lewit and Coate (1982). Based from the literature reviewed, we found that researchers have focused attention on teens when examining the association between cigarette taxes and smoking, and most studies report evidence that teens reduce consumption when prices (taxes) are increased and that the price responsiveness of teens is greater than that for adults (Gallet \& List 2003). In our study, we have also examined these previous findings and found out significant differences between the responsiveness of youth and adults smokers to price change.

The Sin Tax Law works its effects trough altering the market determined price of tobacco market structure by making the cost of producing the products relatively expensive - a cost-push mechanism that firms transfer its cost to the consumer translating to a higher buying price in the market for cigarettes. Hence, the effectiveness of the Sin Tax Law could likely be seen on how the Filipino citizens respond to these price changes. By identifying the price elasticity of the smokers, their responsiveness towards the price would be determined. Results of the study served as one of the bases in evaluating the government's goals regarding Sin Tax Law. If the cigarette consumption is fairly inelastic, then it could not be directly argued that Sin Tax Law reduces consumption of cigarettes. Conversely, if it is elastic, then higher taxes should discourage smoking. Taking into account the heterogeneity of the population, the study considered different subgroups and have been observed separately. This present study consider the youth smokers (ages 11-17 years) and adult smokers (ages 18years and above). An analysis of the effect of Sin Tax Law on cigarette consumption would determine the comparative behavior towards smoking between these two subgroups.

Furthermore, the change in smoking behavior of the smokers before and after the implementation of Sin Tax Law (STL) was evaluated using the Difference-In-Difference regression analysis. If the smokers are not responsive with respect to prices due to addiction, then it can be concluded that the law might not be effective in reducing consumption. This research attempts to fill this knowledge gap and provide insights into these issues, addressing the role and potential impacts of Sin Tax Law for the stakeholders of this policy, especially the young and adult smokers. 


\section{METHODLOGY}

The hypothesis and focus of this study is that, on average, smokers will respond to increasing prices of cigarettes. This will potentially prevent young or adult from smoking. However, to effectively evaluate this hypothesis other important socio-economic variables need to be taken into consideration.

Several factors may affect the decision to change their smoking behavior. Figure 1 presents the determinants of cigarette consumption. This study used socio-demographic, social influence, smoking policy, media and economics variables. Socio-demographic factors included age, gender, marital status, household size, education, religion and distance of house to store. Social influence referred to friend smoking and family smoking. Smoking policy referred to the restriction of smoking in public places and at private worksites. Media included the pro-smoking and antismoking advertisement. Economic variable refers to price and income.

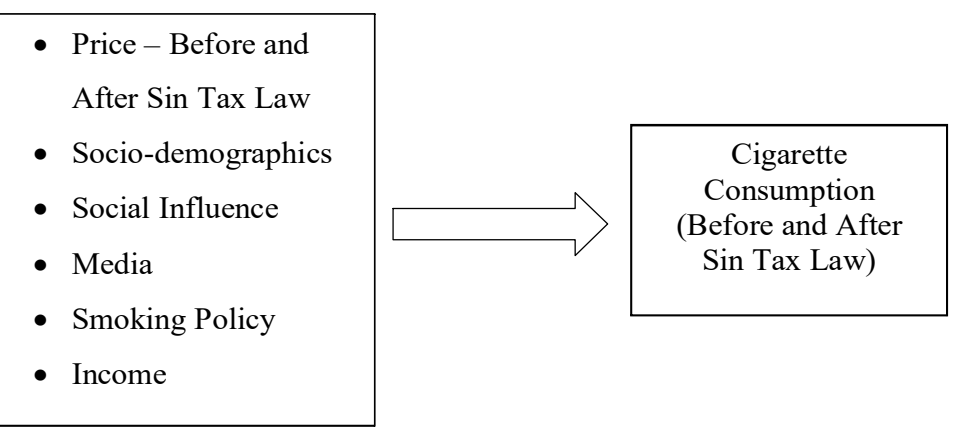

Figure 1. Determinants of cigarette consumption

The demand for cigarette can also be determined on how it changes with respect to the change of price through the theory of elasticity of demand. Price elasticity of demand refers to the extent to which use of a product falls or rises after increases or decreases in its price. In other words, it measures the responsiveness of demand after a change in price. The formula in calculating the price elasticity of demand is:

$\%$ change in quantity demanded

Price elasticity of Demand (Ped)

$\%$ change in price 
In every coefficient of price elasticity of demand has different corresponding indication. If $P e d=0$, demand is perfectly inelastic which means demand does not change at all when price changes. If Ped is between 0 and 1 , demand is inelastic indicating that the change of demand is lesser than the change of price. If Ped $=1$, meaning the demand is unitary and there is equal change between demand and price. If Ped $>1$, demand is elastic implying that demand responds more than proportionately to a change in price (Besanko \& Braeutigam 2010).

Data Analysis

The researcher used the descriptive (non-econometric) and econometric analysis using STATA. Data were obtained from 191 respondents (98 adults, 93 youth) from Mahaplag Leyte, Philippines. We used structured questionnaire to conveniently extract the most valuable data from the residents. To identify the factors affecting cigarette consumption, we used ordinary least square (OLS) for it is popularly used in estimating the parameter of multiple regression model. Further, in investigating the effect of Sin Tax Law whether cigarette consumption has changed overtime, pooled cross section analysis was used. To check the validity of results, several diagnostic tests were also conducted.

\section{Econometric Model}

In this study, the following model was postulated to analyze the determinants of cigarette consumption. The dependent variable was the average number of cigarette consumed daily. The multiple regression model was postulated as follows:

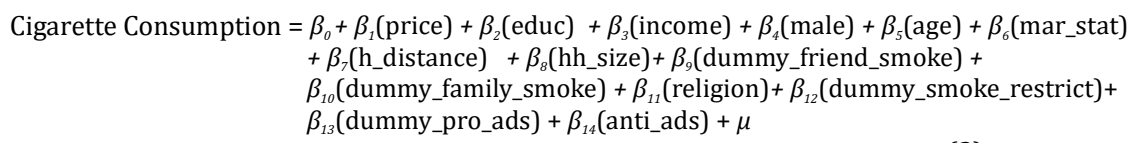

where:

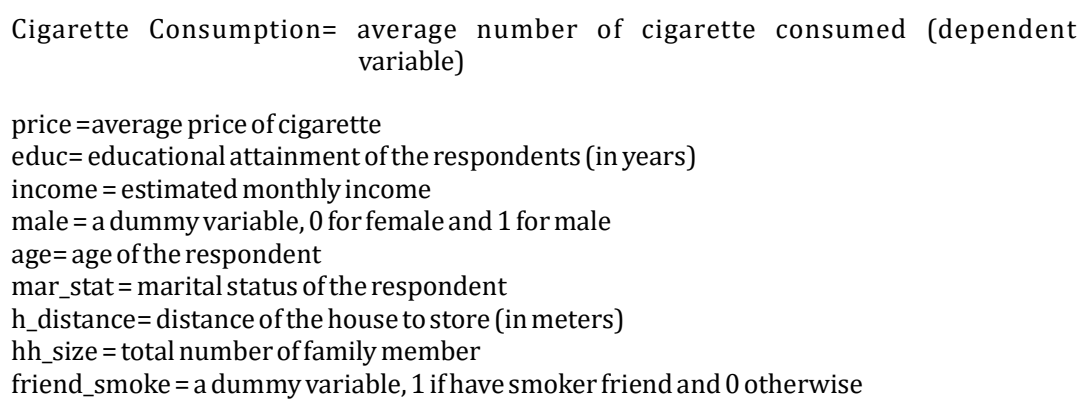


family_smoke $=$ a dummy variable, 1 if have smoker family member and 0 otherwise religion= religion of the respondent in different denomination. smoke_restrict= a dummy variable, 1 if there is smoking restriction and 0 otherwise pro_ads $=$ a dummy variable, 1 if aware of pro-smoking advertisementand 0 otherwise anti-ads = a dummy variable, 1 if aware of anti-smoking advertisement and 0 otherwise $\mu=$ error term

For difference-in-differences where change in cigarette consumption was estimated, a time and dummy treatment variable was used in the regression framework. The following regression model was analyzed.

$\begin{aligned} \text { Cigarette Consumption it }= & \beta_{0}+\beta_{1}(\text { smoking it })+\beta_{2}(\operatorname{after} \operatorname{Sin} \text { Tax Law it })+ \\ & \left.\beta_{3} \text { (smoking it *after Sin Tax Law it }\right)+\mu\end{aligned}$

where:

smoking = a dummy variable, 0 for non-smokers and 1 for smokers

after $\operatorname{Sin}$ Tax Law = a dummy variable, 1 if after Sin Tax Law and 0 otherwise

smoking*after Sin Tax Law = interaction effect and capture the impact of $\sin$ tax

$\mu=$ error term

\section{RESULTS AND DISCUSSION}

\section{Price of Cigarette and Smoking Habit}

The Sin Tax Law effects on prices of cigarettes by altering the market determined price through price intervention and regulation set by government. As shown in Table 1, the average price of cigarette per stick before STL was lower ( $₹ 1.11 /$ stick) compared to ( $\$ 2.45 /$ stick) after. Furthermore, the respondents mentioned that before STL, there were times they could buy as low as 25 centavos per stick of cigarette, and remembered that two pesos is the only maximum price. However, 2.45 pesos per stick after STL, cigarette prices become expensive. The cheapest price went to and had reached $尹 4$ per stick at the maximum. These increases in average prices and price range actually indicated the direct effect of Sin Tax Law to the prices of cigarettes.

\section{Changes in Frequency of Smoking}

Table 1 shows the change in the average cigarette consumption of adult and youth smokers. Before STL, youth smokers had larger average consumption compared to adult smokers. Adult smokers only consumed around 11 sticks of cigarette per day while youth smokers consumed 21 sticks of cigarette per day. After the implementation of STL, average cigarette consumption of adult and youth smokers changed in different 
direction. Despite increase in the price of cigarette, average cigarette consumption of adult smokers increased to Figures approximately 12 sticks which was an increase of about $9 \%$. In contrast, average cigarette consumption of youth smokers decreased from 21 sticks to around 4 sticks, a significant decrease of about $80 \%$.

Table 1. Average cigarette consumption per day of adult and youth smokers

\begin{tabular}{cccc}
\hline \hline $\begin{array}{c}\text { Cigarette Consumption } \\
\text { (Stick) }\end{array}$ & $\begin{array}{c}\text { Before } \\
\text { (Mean) }\end{array}$ & $\begin{array}{c}\text { After } \\
\text { (Mean) }\end{array}$ & Net Change \\
\hline Adult & 11 & 12 & $9 \%$ \\
Youth & 21 & 4 & $-81 \%$ \\
\hline
\end{tabular}

\section{Cigarette Expenditure}

Adult and youth smokers had differed in terms of average cigarette expenditure (Table 2). On average, both adult and youth smokers spent P17.25 per day before STL. After STL, for adult, cigarette expenditure increased on average to $\mathrm{P} 29.92$ (73.45\% increase) while for youth, it decreased to $尹 10$ per day, a $36.23 \%$ reduction.

Table 2. Average cigarette expenditure per day of adult and youth smokers

\begin{tabular}{cccc}
\hline \hline $\begin{array}{c}\text { Cigarette Expenditure } \\
\text { (per day) }\end{array}$ & Before & After & \\
& (Mean) & (Mean) & Net Change \\
\hline Adult & 17.25 & 29.92 & $73.45 \%$ \\
Youth & 17.25 & 9.77 & $-36.23 \%$ \\
\hline
\end{tabular}

\section{Econometric Estimation}

Determinants of Cigarette Consumption

Cigarette consumption of individual is affected by different factors. The study used price as the main explanatory variable for cigarette consumption. We controlled several socio-demographic variables. For comparison, before and after Sin Tax Law data were analyzed using multiple regression analysis.

Table 3 shows the estimate of a functional relationship between cigarette consumption (dependent variable) and independent variables for adult smokers. The two models were significant since the p-value of $\mathrm{F}$ statistics was less than $1 \%$. 
The first model (before Sin Tax Law) had 0.497 R-squared. This implies that $49.7 \%$ of the variation of dependent variable can be explained by the model. Among all the independent variables, only two variables were significant, price of cigarette per stick and distance of house to store. Price of cigarette per stick was positively associated with cigarette consumption. It means that for every 1-peso increase in price, cigarette consumption would also increase by 6.595 sticks. This would indicate that cigarette is a Giffen good. This condition happened because income effect dominates substitution effect. Also, cigarette products have only few substitutes, therefore consumers tend to buy more of these goods with their increase income coupled with its continuous habit of consumption. Also, it is important to note that elasticity of demand in the micro level may depend not just on price, but on relative income price (RIP) as studied by Kan (2007). In the case of Mahaplag tobacco consumers, income effect dominated substitution effect. Therefore, they are less responsive to price change. In addition, behavioural responses are subjected to changes with different factors including the demographic and economic characteristics of the surveyed respondents. On the contrary, distance of house to store has negative association with cigarette consumption. A 1-meter increase in distance is associated with a 0.0405 reduction in cigarette consumption. This suggests that, smokers living far from the store consumed less cigarette compared to those who lived near.

In the second model, the R-squared had increased to 0.70 . It showed that $70 \%$ of the variation of cigarette consumption can be explained by the independent variables. Compared to the first model, this model (after Sin Tax Law) now had four significant variables. This included price of cigarette per stick, age, household size, and marital status. Price had still positive relationship with cigarette consumption; however, the coefficient was relatively lower. With the intervention of Sin Tax Law, a 1-peso increase in price is associated with a 4.859 increase in cigarette consumption. Before Sin Tax Law, the coefficient of price was 6.595. After Sin Tax Law, the coefficient of price was relatively lower at 4.859. Cigarette is still considered as Giffen good since it faces an upward sloping demand curve. This condition may exist with highly demanded products but fewer substitutes like cigarettes. Age could now explain the dependent variable. The result shows that as respondents get older cigarette consumption will decrease by 0.0806 sticks. Household size had also negative relationship with cigarette consumption. More members in the family was associated with 0.598 reduction in cigarette consumption. This model is referring to adult smokers, and most of them were parents. And therefore, if they had a bigger household size, they would probably lower their consumption for cigarette maybe to compensate the budget for daily needs. Lastly, being married was positively related to cigarette consumption. If an individual 
was married, their consumption for cigarette was higher by 2.089 sticks compared to unmarried individual. Married individuals as surveyed in the study had higher income, therefore had higher financial capacity to buy cigarette products. Thus, results from the analysis indicated married respondents were less responsive to price change, and the probability of consuming more cigarettes was higher if married.

Table 3. Multiple regression model on determinants of cigarette consumption among adult

\begin{tabular}{|c|c|c|}
\hline VARIABLES & $\begin{array}{c}(1) \\
\text { (Before) }\end{array}$ & $\begin{array}{c}(2) \\
\text { (After) }\end{array}$ \\
\hline Price & $\begin{array}{c}6.595 * * * \\
(1.366)\end{array}$ & $\begin{array}{c}4.859 * * * \\
(0.609)\end{array}$ \\
\hline Age & $\begin{array}{l}-0.0522 \\
(0.0443)\end{array}$ & $\begin{array}{c}-0.0806^{* *} \\
(0.0378)\end{array}$ \\
\hline Male & $\begin{array}{c}2.088 \\
(1.407)\end{array}$ & $\begin{array}{c}0.370 \\
(1.023)\end{array}$ \\
\hline Household size & $\begin{array}{l}-0.162 \\
(0.426)\end{array}$ & $\begin{array}{l}-0.598^{*} \\
(0.320)\end{array}$ \\
\hline Single & $\begin{array}{l}-2.497 \\
(1.772)\end{array}$ & $\begin{array}{l}-1.261 \\
(1.368)\end{array}$ \\
\hline Living with a partner & $\begin{array}{l}-0.645 \\
(2.586)\end{array}$ & $\begin{array}{l}-1.651 \\
(1.566)\end{array}$ \\
\hline Married & $\begin{array}{c}1.213 \\
(1.190)\end{array}$ & $\begin{array}{l}2.089 * \\
(1.079)\end{array}$ \\
\hline Catholic & $\begin{array}{c}1.764 \\
(1.814)\end{array}$ & $\begin{array}{l}-0.493 \\
(0.831)\end{array}$ \\
\hline Protestant & $\begin{array}{c}1.533 \\
(1.886)\end{array}$ & $\begin{array}{l}-1.227 \\
(1.063)\end{array}$ \\
\hline Education & $\begin{array}{l}0.0156 \\
(0.146)\end{array}$ & $\begin{array}{c}0.143 \\
(0.109)\end{array}$ \\
\hline Income & $\begin{array}{c}-8.17 e-05 \\
(0.000103)\end{array}$ & $\begin{array}{l}-7.52 \mathrm{e}-05 \\
(7.12 \mathrm{e}-05)\end{array}$ \\
\hline Distance of house to store & $\begin{array}{l}-0.0405^{*} \\
(0.0215)\end{array}$ & $\begin{array}{c}-0.000884 \\
(0.0188)\end{array}$ \\
\hline Have smoker friend & $\begin{array}{c}0.124 \\
(0.865)\end{array}$ & $\begin{array}{c}0.623 \\
(0.720)\end{array}$ \\
\hline Have smoker family member & $\begin{array}{l}-0.605 \\
(1.230)\end{array}$ & $\begin{array}{l}-0.576 \\
(0.913)\end{array}$ \\
\hline Smoking allowed in worksite & $\begin{array}{l}-0.409 \\
(1.904)\end{array}$ & $\begin{array}{c}1.696 \\
(1.162)\end{array}$ \\
\hline Smoking allowed in home & $\begin{array}{c}1.451 \\
(1.263)\end{array}$ & $\begin{array}{c}-0.0252 \\
(0.745)\end{array}$ \\
\hline Anti-smoking advertisement & $\begin{array}{l}-0.224 \\
(0.300)\end{array}$ & $\begin{array}{r}-0.0177 \\
(0.213)\end{array}$ \\
\hline Pro-smoking advertisement & $\begin{array}{c}0.142 \\
(0.496)\end{array}$ & $\begin{array}{c}-0.0289 \\
(0.327)\end{array}$ \\
\hline Constant & $\begin{array}{c}2.829 \\
(4.053)\end{array}$ & $\begin{array}{c}3.236 \\
(2.606)\end{array}$ \\
\hline Observations & 98 & 98 \\
\hline R-squared & 0.497 & 0.700 \\
\hline
\end{tabular}

Note: Robust standard errors in parentheses ${ }^{* * *} \mathrm{p}<0.01,{ }^{* *} \mathrm{p}<0.05,{ }^{*} \mathrm{p}<0.1$ 
Table 4 shows what determines the cigarette consumption of youth smokers before and after Sin Tax Law. The table confirms how the dependent variable is affected by the explanatory variables. Both models displayed are significant at $1 \%$.

In Model $1,56 \%$ of the variation of cigarette consumption can be explained by the independent variables. There were only three variables which significantly affected cigarette consumption. These included price of cigarette per stick, distance of house to store and smoking policy in home. Positive relationship between price of cigarette and cigarette consumption was observed. A 1-peso increase in price was associated with 11.90 sticks increase in cigarette consumption. In this condition, cigarette also considered as giffen good, meaning as price increases quantity demanded increases. Inversely, distance of house to store was negatively related to the dependent variable. In every 1-meter increase in distance, cigarette consumption decreased by 0.216 stick. The coefficient of smoking policy in home was positive, implying a direct relationship with cigarette consumption. If smoking was allowed in the home of individuals, their cigarette consumption was higher by 4.26 sticks compared to those who were restricted in their home.

The second model had higher R-squared compared to the first model. Model 2 shows that $59 \%$ of the variation of cigarette consumption can be explained by the explanatory variables. It can be noticed that there were two more significant independent variables captured in Model 2. This suggests that cigarette consumption among youth was affected by time. Price of cigarette and smoking policy in home were positive. This result was consistent with the first model. However, there are differences in coefficients. A 1-peso increase in price would bring cigarette consumption to a 1.322 sticks. This big change is an indication that cigarette demand of youth was very responsive to price changes. Before Sin Tax Law, the coefficient of price was 11.90. After Sin Tax Law, the coefficient of price dropped to 1.32. This implies that the increase in prices of cigarettes contributed to the huge reduction in cigarette consumption among underage smokers. Consequently, Sin Tax Law was positively impacting the youth. This shows that youth were discouraged to consume more cigarettes because of the associated increase in price.

Other variables such as being Catholic, Born Again and distance of house to store have negative association with cigarette consumption. The negative association between being Catholic and cigarette consumption reflects the influence of religion on vices. Born Again, Youth consumed less compared to non-Born Again youth. Because they claimed that in their religious practices, smoking is prohibited. Distance of house to store influenced the number of cigarette consumed by youth. Its relationship with cigarette consumption was negative consistent with previous 
findings. Nonetheless, the coefficient was declined which signifying that having a long distance of house to store would have less impact to cigarette consumption. Quantitatively, in every 1-meter increase in distance, cigarette consumption of youth decreased by 0.0681 stick.

Table 4. Multiple regression model estimates on determinants of cigarette consumption among youth

\begin{tabular}{|c|c|c|}
\hline VARIABLES & $\begin{array}{c}(1) \\
\text { (Before) }\end{array}$ & $\begin{array}{c}(2) \\
\text { (After) }\end{array}$ \\
\hline Price & $\begin{array}{c}11.90 * * \\
(5.448)\end{array}$ & $\begin{array}{c}1.322 * * * \\
(0.288)\end{array}$ \\
\hline Age & $\begin{array}{c}0.377 \\
(0.448)\end{array}$ & $\begin{array}{c}0.320 \\
(0.204)\end{array}$ \\
\hline Male & $\begin{array}{c}0.490 \\
(1.192)\end{array}$ & $\begin{array}{c}0.377 \\
(0.363)\end{array}$ \\
\hline Household size & $\begin{array}{c}0.138 \\
(0.290)\end{array}$ & $\begin{array}{c}0.0356 \\
(0.0805)\end{array}$ \\
\hline Catholic & $\begin{array}{c}-8.366 \\
(7.720)\end{array}$ & $\begin{array}{c}-3.653^{*} \\
(1.872)\end{array}$ \\
\hline Born Again & $\begin{array}{l}-11.38 \\
(8.199)\end{array}$ & $\begin{array}{c}-4.096 * * \\
(1.943)\end{array}$ \\
\hline Protestant & $\begin{array}{c}-5.594 \\
(8.226)\end{array}$ & $\begin{array}{l}-0.532 \\
(2.876)\end{array}$ \\
\hline Education & $\begin{array}{l}-0.526 \\
(0.626)\end{array}$ & $\begin{array}{l}-0.0441 \\
(0.173)\end{array}$ \\
\hline Income & $\begin{array}{l}-0.0591 \\
(0.0521)\end{array}$ & $\begin{array}{c}0.00323 \\
(0.00651)\end{array}$ \\
\hline Distance of house to store & $\begin{array}{c}-0.216^{*} \\
(0.117)\end{array}$ & $\begin{array}{c}-0.0681^{* *} \\
(0.0329)\end{array}$ \\
\hline Have smoker friend & $\begin{array}{c}0.591 \\
(1.108)\end{array}$ & $\begin{array}{l}-0.147 \\
(0.354)\end{array}$ \\
\hline Have smoker family member & $\begin{array}{l}-0.939 \\
(0.931)\end{array}$ & $\begin{array}{l}0.0511 \\
(0.415)\end{array}$ \\
\hline Smoking allowed in school & $\begin{array}{c}17.17 \\
(11.82)\end{array}$ & $\begin{array}{r}-0.0358 \\
(0.853)\end{array}$ \\
\hline Smoking allowed in home & $\begin{array}{c}4.260 * * \\
(2.035)\end{array}$ & $\begin{array}{l}1.561 * \\
(0.845)\end{array}$ \\
\hline Anti-smoking advertisement & $\begin{array}{l}0.0639 \\
(0.409)\end{array}$ & $\begin{array}{r}-0.0257 \\
(0.167)\end{array}$ \\
\hline Pro-smoking advertisement & $\begin{array}{c}-0.0138 \\
(0.441)\end{array}$ & $\begin{array}{c}0.112 \\
(0.205)\end{array}$ \\
\hline Constant & $\begin{array}{c}10.46 \\
(8.186)\end{array}$ & $\begin{array}{l}-0.702 \\
(2.978)\end{array}$ \\
\hline Observations & 93 & 93 \\
\hline R-squared & 0.560 & 0.590 \\
\hline
\end{tabular}

Note: Robust standard errors in parentheses ${ }^{* * *} \mathrm{p}<0.01,{ }^{* *} \mathrm{p}<0.05,{ }^{*} \mathrm{p}<0.1$ 
Effects of Sin Tax Law on Cigarette Consumption

There are various methods in investigating the effect of time the outcomes of a particular variable. In this study, we used the Difference-inDifference (DiD) method in that need and treatment dummy variable. Table 5 shows how cigarette consumption of adult and youth smokers changed overtime. The model contained the following variables: cigarette consumption as dependent variable, smoking (treatment), after Sin Tax Law (time) and the interaction effect (treatment*time) as independent variables. The interaction effect captures the impact of Sin Tax Law.

The result shows that cigarette consumption of adult smokers had no significant change over time in spite of price increase due to Sin Tax Law. The most important reason is the fact that cigarette is addictive. Additionally, adult smokers were most likely experienced smokers who have developed a strong habit of smoking. It could be that the increase in cost of cigarette due to Sin Tax Law was not enough to abandon their smoking habit which indeed took time to develop. In fact, they were working, thus could afford to buy cigarettes even when prices were higher after Sin Tax Law. This suggests that adults were unresponsive to price increase in cigarettes. This implies that Sin Tax Law was not able to discourage adults from smoking but eventually helped increase the revenue derived from cigarette consumption. In contrast, youth smokers had significant change with their consumption. After Sin Tax Law, their cigarette consumption significantly lowered down. It can be confirmed that youths were price responsive. This finding is consistent to the study of Lewit and Coate (1982). This effect was most likely a result of the lower purchasing power of the youths who were dependent on parents. Hence, their cigarette consumption was proportionate to the money or allowance they got from their parents. As more tax will be levied put on cigarette, possibly there will be fewer youth smokers in the future. However, it is not totally the price influencing their consumption. There are many things to consider that might bring changes through time.

Table 5. Pooled OLS regression estimates on cigarette consumption

\begin{tabular}{lcc}
\hline & $(1)$ & $(2)$ \\
VARIABLES & Adult & Youth \\
\hline Smoking & $11.30^{* * *}$ & $21^{* * *}$ \\
& $(1.032)$ & $(1.490)$ \\
After Sin Tax Law & $7.68 \mathrm{e}-15$ & $1.06 \mathrm{e}-15$ \\
& $(0.837)$ & $(0.640)$ \\
Smoking*After Sin Tax Law & 0.530 & $-16.84 * * *$ \\
& $(1.478)$ & $(1.814)$ \\
Constant & $-6.66 \mathrm{e} 16$ & $-6.66 \mathrm{e}-16$ \\
& $(0.599)$ & $(0.437)$ \\
Observations & 196 & 186 \\
R-squared & 0.561 & 0.544 \\
\hline
\end{tabular}

Note: Standard errors in parentheses ${ }^{* * *} \mathrm{p}<0.01,{ }^{* *} \mathrm{p}<0.05,{ }^{*} \mathrm{p}<0.1$ 


\section{CONCLUSIONS}

This research examined the effects of Sin Tax Law at the micro-level data through different behavioral responses of two different age groups, in Mahaplag, Leyte, Philippines. Using the before-and-after method of analyzing impact, we applied a multiple regression analysis incorporating difference-in-difference approach of econometric estimation. The study found out that Sin Tax Law only significantly lowered cigarette consumption among youth, but there was no significant influence among adults. In a two-year intervention of Sin Tax Law, cigarette consumption of youth had reduced. This information conforms from previous studies that youth is more price responsive than adult. In addition, results show that cigarette consumption of adult and youth had different determinants varying over time. Cigarette consumption of adult smokers before Sin Tax Law appeared to be positively related with the price of the product and negatively related with the distance of house to store. After Sin Tax Law it is found that aside price and distance to store, being married also positively affected cigarette consumption. On the other hand, cigarette consumption of youth before Sin Tax Law was significantly affected by price, distance of house to store and smoking policy at home. Type of religion affiliation appeared to also negatively influence cigarette consumption. Indeed, this study revealed that Sin Tax Law through its effect on the cigarette's selling buying price clearly achieved its objective of regulating the smoking behavior of young smokers, thus, seen effective. Adults, however, are irresponsive to price change. It is recommended that specific policies and regulations targeting adult smokers be formulated and strictly implemented. A suggestion of shifting the paradigm of controlling this behavior into an incentive based mechanism coupled with standardized packaging for tobacco products are seen to likely address this concern.

\section{REFERENCES}

BESANKO, D., AND BRAEUTIGAM R. (2010). "Microeconomics $-4^{\text {th }}$ Edition". WILEY, United States of America.

BISHOP, JOHN A. AND YOO, JANG H. 1985. Health Scare,' Excise Taxes and Advertising Ban in the Cigarette Demand and Supply. Southern Economic Journal, 52(4), pp.402-11.

BLECHER, E., AND VAN WALBEEK, C. (2008). "An analysis of Cigarette Affordability". Paris: International Union Against Tuberculosis and Lung Disease.

CHALOUPKA, F. J. (1991). Rational Addictive Behavior and Cigarette Smoking. Journal of Political Economy, 99: 722-42. 
DOUGLAS, S. M., AND G. HARIHARAN. (1994). The Hazard of Starting Smoking: Estimates from a Split Sample Duration Model. Journal of Health Economics 13, 213-230.

EVANS, W. N., AND M. C. FARRELLY. (1995). The Compensating Behavior of Smokers: Taxes, Tar and Nicotine,Working paper, Department of Economics, University of Maryland.

GALLET, C.A. AND J.A. LIST. (2003). Cigarette Demand: A Meta-Analysis of Elasticities. Health Economics 12(10): 821-835.

GROSSMAN, M., D. COATE, E.M. LEWIT, AND R.A. SHAKOTKO (1983), "Economic and Other Factors in Youth Smoking" Final Report, National Science Foundation.

HARRIS, JEFFREY E. (1985). "On the Fairness of Cigarette Excise Taxation" The Cigarette Excise Tax. Cambridge, MA: Institute for the Study of Smoking Behavior and Policy, John F. Kennedy School of Government, Harvard University, pp. 106-11

KAN, M. (2007). Investigating cigarette affordability in 60 cities using cigarette price-dailyincome ratio. Tobacco Control, 429-432.

LEWIT, E. M., D. COATE, AND M. GROSSMAN. (1981). The Effects of Government Regulations on Teenage Smoking. Journal of Law and Economics, 24: 545-69.

LEWIT, E. M., AND D. COATE. (1982). The Potential for Using Excise Taxes to Reduce Smoking. Journal of Health Economics, 1: 121-45, 1982.

MANNING, W., KEELER E., NEWHOUSE J., SLOSS E., AND WASSERMAN J. (1991). The Costs of Poor Health Habits. Cambridge Mass: Harvard University Press.

NATIONAL CANCER INSTITUTE (1993). The Impact of Cigarette Excise Taxes on Smoking Among Children and Adults: Summary Report of a National Cancer Institute Expert Panel. Bethesda, Maryland: National Cancer Institute, Division of Cancer Prevention and Control, Cancer Control Science Program.

NGUYEN, C. V. (2012). "Demographic and Socio-economic Determinants of Smoking: Evidence from Vietnam”, Economics Bulletin, Vol. 32 No. 3 pp. 2300- 2312

ULEP, V.G. (2012). "The Impact of Sin Tax Law on the Affordability of Cigarette in the Philippines. Health Justice Philippines, Inc. and the Southeast Asia Tobacco Control Alliance.

WASSERMAN, JEFFREY, WILLARD G. MANNING, JOSEPH P. NEWHOUSE, AND JOHN D. WINKLER. (1991). "The Effects of Excise Taxes and Regulations on Cigarette Smoking". Journal of Health Economics 10: 4364.

XIAOHUI HOU, XIAOCHEN XU, AND IAN ANDERSON. (2015). Determinants of Tobacco Consumption in Papua New Guinea: Challenges in Changing Behaviors. Health Nutrition and Population Global Practice Group 